\title{
TINGKAT PENGUASAAN TATA BAHASA BAKU BAHASA INDONESIA OLEH GURU BAHASA INDONESIA SMA DI KABUPATEN LAMONGAN
}

\author{
Markub \\ Laila Tri Lestari \\ Universitas Islam Darul Ulum Lamongan
}

\begin{abstract}
Abstrak: Tujuan umum penelitian ini adalah mendeskripsikan tingkat penguasaan Tata Bahasa Baku Bahasa Indonesia oleh guru bahasa Indonesia SMA di Kabupaten Lamongan dan memeringkat tata bahasa yang paling sulit bagi guru bahasa Indonesia di Kabupaten Lamongan. Penelitian ini dirancang dalam penelitian deskriptif kuantitatif. Yang menjadi sumber data penelitian ini adalah guru bahasa Indonesia SMA di Kabupaten Lamongan. Penganalisisan data penelitian ini dilakukan secara kuantitatif. Hasil penelitian menunjukkan bahwa tingkat penguasaan TBBBI oleh guru bahasa Indonesia SMA tergolong sedang dengan rerata skor 63. Peringkat kesulitan tata bahasa bagi guru bahasa Indonesia SMA yang paling tinggi adalah tata kalimat (skor 60), disusul berturut-turut tata kata (skor 64) dan tata bunyi (skor 66).
\end{abstract}

Kata kunci: penguasaan, guru SMA, tata bahasa baku bahasa Indonesia

Abstract: The general objective of this study is to describe the level of mastery of grammar Baku Indonesian by Indonesian teacher from high school in Lamongan and rank the most difficult grammar for Indonesian teachers in Lamongan. This study was designed in a quantitative descriptive study. The source of research data is a teacher Indonesian high school in Lamongan. Analyzing data is performed quantitative research. The results showed that the level of mastery TBBBI by Indonesian high school teachers were moderate with a mean score of 63. Rating grammatical difficulties for Indonesian teachers the highest high school is the syntax (score 60), followed by successive order of words (score 64) and sound system (score 66).

Keywords: mastery, high school teacher, grammar raw Indonesian

\section{PENDAHULUAN}

Bahasa Indonesia berkedudukan sebagai bahasa nasional sekaligus sbagai bahasa negara. Bahasa Indonesia diakui sebagai bahasa nasional sejak Sumpah Pemuda tahun 1928 dan dikukuhkan sebagai bahasa negara sejak disahkannya Undang-Undang Dasar 1945 (Halim, 1976:145). Bahasa Indonesia yang berasal dari bahasa Melayu haruslah dibina karena kebutuhan mengharuskan bahasa Indonesia itu berubah. Perubahan itu tetap dengan memperhatikan identitasnya dan selama tidak merugikan perkembangan bahasa yang menuju bahasa standar atau baku (Medan, 1988:112).

Usaha modernisasi adalah hal yang terpenting. Usaha standardisasi dan penyiapan bacaan mesti dianggap sebagai alat untuk melakukan usaha modernisasi itu (Alisyahbana, 1984:48). Usaha modernisasi bahasa di antaranya berupa standardisasi atau pembakuan bahasa Indonesia. Modernisasi bahasa Indonesia itu tidak hanya mengenai konsep-konsep 
yang terjelma dalam kata-kata, tetapi juga mengenai aturan pembentukan kata-kata dan kalimat. Dengan kata lain, modernisasi bahasa harus meliputi modernisasi tata bahasa (Alisyahbana, 1984:50-51).

Modernisasi tata bahasa ini merupakan tugas Badan Bahasa. Tugas terpentingnya adalah membandingkan bermacam-macam kemungkinan dan memilih yang paling logis dan sesuai dengan suasana dan cara berpikir kebudayaan modern dan kalau mungkin juga yang paling luas dapat diterima dan dipahamkan berdasarkan sifat bahasabahasa Indonesia atau Melayu dalam arti yang luas (Alisyahbana, 1984:50). Usaha modernisasi yang dilakukan badan tersebut berlangsung dari tahun ke tahun. Pada tahun 1988 berhasil diterbitkan Kamus Besar Bahasa Indonesia (selanjutnya disingkat $\mathrm{KBBI}$ ) dan Tata Bahasa Baku Bahasa Indonesia (selanjutnya disingkat TBBBI). TBBBI kali pertama terbit pada tahun 1988 edisi pertama, kemudian terbit lagi pada tahun 1993 edisi kedua dengan cetakan terbatas, terakhir pada tahun 1998 terbit TBBBI edisi ketiga.

Adanya beberapa kali revisi terhadap TBBBI itu menunjukkan bahwa terdapat perbedaan konsep atau pandangan di antara para pakar bahasa baik yang terlibat secara langsung dalam penyusunan TBBBI tersebut maupun yang tidak terlibat secara langsung. Selain itu, meskipun sudah ada TBBBI yang dari segi judulnya saja menunjukkan bahwa buku ini merupakan satu-satunya buku pedoman yang sudah disahkan oleh Badan Bahasa dan harus diberlakukan di Indonesia, masih saja banyak pakar bahasa yang tidak setuju terhadap kaidah-kaidah yang terdapat di dalamnya. Pada umumnya mereka kemudian membuat tulisan-tulisan ilmiah atau semiilmiah dalam bentuk buku atau jurnal ilmiah yang isinya berbeda bahkan bertentangan dengan kaidah yang terdapat dalam TBBBI. Hal inilah yang menciptakan kebingungan bagi pemakai bahasa Indonesia.

Selain ada dua macam TBBBI yang pernah berlaku dan tentu saja masih beredar di masyarakat yakni TBBBI edisi pertama terbitan tahun 1988 dan TBBBI edisi kedua terbitan tahun 1993, juga terdapat buku-buku tata bahasa yang disusun para pakar bahasa Indonesia. Di antara buku-buku tata bahasa bahasa Indonesia tersebut, manakah yang saat ini dijadikan pedoman dalam berbahasa Indonesia belumlah ada informasinya. Bahkan timbul pertanyaan lebih jauh lagi, "Sudahkah masyarakat pemakai bahasa memedomani TBBBI dalam berbahasa dalam situasi resmi?" Pertanyaanpertanyaan itulah yang mendorong peneliti melakukan penelitian tentang tingkat penguasaan TBBBI oleh guru bahasa Indonesia.

Guru bahasa Indonesia dipilih sebagai subjek penelitian karena menjadi ujung tombak dalam pembinaan bahasa Indonesia. Dalam proses pengenalan dan pembinaan bahasa, sekolah memiliki peran sentral. Alisjahbana (dalam Moeliono, 1985:28) menekankan pentingnya sistem persekolahan bagi penyebaran bahasa baku (Moeliono, 1985:29). Sekolah sebagai lembaga pendidikan formal harus difungsikan sebagai basis pembinaan bahasa Indonesia sehingga terlahir generasi yang setia dan bangga pada bahasa Indonesia. Para siswa harus dibiasakan menerapkan hasil-hasil kodifikasi bahasa Indonesia sesuai dengan pandangan Skinner (1957) yang menyatakan bahwa penguasaan bahasa pada hakikatnya merupakan suatu proses pembentukan kebiasaan. Kebiasaan itu dapat terjadi melalui peniruan, yaitu menirukan rangsangan dengan perilaku yang cukup sering atau secara bertubi-tubi (Yulianto, 2007:13). Melalui kegiatan ini akan terbentuklah 
kebiasaan secara bawah sadar pada diri siswa dan memperoleh kemampuan menghasilkan unsur-unsur bahasa itu secara otomatis.

Dengan demikian, guru bahasa Indonesia harus lebih dulu menguasai TBBBI karena tersosialisasikan tidaknya TBBBI di sekolah tergantung sepenuhnya di tangan para guru terutama guru bahasa Indonesia. Jika guru bahasa Indonesia sudah menguasai TBBBI, mereka bisa menyosialisasikannya sedikit demi sedikit secara bertahap kepada para siswa. Hal ini sesuai dengan hipotesis input (masukan) yang menyatakan bahwa seseorang memperoleh bahasa melalui input (masukan) yang dapat dipahami, yaitu dalam bentuk pesan atau makna yang sampai kepadanya (Brown, 2000:278). Perkembangan atau penguasaan bahasa anak bertambah dari satu tingkat (disebut tingkat i) ke tingkat yang lebih tinggi (disebut $\mathrm{i}+1$ ) dalam suatu urutan alamiah. Rumus $\mathrm{n}+1$ tersebut berarti bahwa seorang siswa yang belajar berbahasa itu hanya akan memperoleh kemajuan dalam belajarnya jika ada tambahan input sedikit demi sedikit dan lebih tinggi dari kemampuannya semula (Baradja, 1990:6).

Berdasarkan paparan di atas, penelitian dengan judul Tingkat Penguasaan Tata Bahasa Baku Bahasa Indonesia oleh Guru Bahasa Indonesia SMA di Kabupaten Lamongan ini sangatlah penting untuk dilakukan.

\section{Perencanaan Bahasa}

Perencanaan bahasa ialah usaha untuk membimbing perkembangan bahasa ke arah yang diinginkan. Perencanaan itu tidak semata-mata meramalkan masa depan berdasarkan apa yang diketahui pada masa lampau, tetapi merupakan usaha yang terarah untuk memengaruhi masa depan itu. Perencanaan bahasa menampilkan perhatian para sarjana terhadap sandi atau kode bahasa yang harus diubah dan produk pengubahannya. Di samping itu, perencanaan bahasa dapat juga dipandang dari sudut pengubahannya (Moeliono, 1985: 5-7).

Haugen (dalam Moeliono, 1985:8) menganjurkan agar perencanaan bahasa dimulai dengan pengetahuan situasi kebahasaan. Setelah itu, disusun program kegiatan yang meliputi sasaran, penetapan garis haluan atau kebijakan untuk mencapai sasaran itu dan sejumlah prosedur untuk melaksanakan program itu.

\section{Fungsi Bahasa Baku}

Ada empat fungsi yang didukung oleh bahasa baku: (1) fungsi pemersatu, (2) fungsi pemberi kekhasan, (3) fungsi pembawa wibawa, dan (4) fungsi sebagai kerangka acuan. Bahasa baku memperhubungkan semua penutur berbagai dialek bahasa itu. Dengan demikian, bahasa baku mmpersatukan mereka menjadi satu masyarakat bahasa dan meningkatkan proses identifikasi penutur orang seorang dengan seluruh masyarakat itu. Fungsi pemberi kekhasan yang diemban oleh bahasa baku memperbedakan bahasa itu dari bahasa yang lain. Karena fungsi itu, bahasa baku memperkuat perasaan kepribadian nasional masyarakat bahasa yang bersangkutan. Pemilikan bahasa baku membawa serta wibawa atau prestise. Fungsi pembawa wibawa bersangkutan dengan usaha orang mencapai kesederajatan dengan peradaban lain yang dikagumi lewat pmerolehan bahasa baku sendiri. Bahasa baku berfungsi sebagai kerangka acuan bagi pemakaian bahasa dengan adanya norma dan kaidah yang jelas. Norma dan kaidah itu menjadi tolok ukur bagi benar tidaknya pemakaian bahasa orang seorang atau golongan. Dengan demikian, 
penyimpangan dari norma dan kaidah dapat dinilai (Alwi, 2000:15).

\section{Pembinaan Bahasa Indonesia}

Pembinaan bahasa Indonesia merupakan upaya yang berhubungan dengan pelaksanaan kegiatan penyebaran bahasa Indonesia ke khalayak sasaran dengan berbagai cara, seperti: penyuluhan, penataran dan pelatihan. Kegiatan-kegiatan itu dapat dilakukan dengan cara tatap muka atau tidak tatap muka. Kegiatan yang dilakukan dengan cara tatap muka dilakukan di ruangan, sedangkan kegiatan yang dilakukan dengan cara tidak tatap muka berlangsung melalui media, baik media cetak, media audio maupun media visual. Pembinaan bahasa juga merupakan upaya meningkatkan mutu penggunaan bahasa melalui proses belajar bahasa di semua jenis dan jenjang pendidikan serta pemasyarakatan bahasa ke berbagai lapisan masyarakat. Pembinaan bahasa dimaksudkan untuk meningkatkan kedisiplinan, keteladanan berbahasa Indonesia dan sikap positif masyarakat terhadap bahasa Indonesia.

Salah satu sasaran pembinaan bahasa adalah memperbaiki sikap bahasa masyarakat. Sikap bahasa (language attitude) adalah posisi mental atau perasaan terhadap bahasa sendiri atau bahasa orang (Kridalaksana,1993). Menurut Arifin dan Tasai (2013:3), sikap bahasa setidaknya mengandung tiga ciri pokok, yaitu kesetiaan bahasa, kebanggaan bahasa, dan kesadaran akan norma bahasa. Kesetiaan bahasa adalah sikap yang mendorong suatu masyarakat tutur mempertahankan kemandirian bahasanya, meskipun apabila perlu, sampai terpaksa mencegah masuknya pengaruh asing. Kebanggaan bahasa merupakan sikap yang mendorong seseorang atau sekelompok orang menjadikan bahasanya sebagai lambang identitas pribadi atau kelompoknya dan sekaligus membedakannya dari orang atau kelompok yang lain.

Usaha pembinaan bahasa dapat juga berupa kegiatan sosialisasi hasilhasil pengembangan. Sosialisasi ini dapat dilakukan melalui berbagai media. Sosialisasi dapat dilakukan melalui media massa baik cetak maupun elektronika. Sosialisasi dapat pula dilakukan melalui pendidikan-pendidikan formal dari SD sampai PT. Dapat pula sosialisasi itu dilakukan melalui penataran para guru dan dosen yang menjadi subjek utama dalam penerapan kaidah tata bahasa di lembaga pendidikan formal. Kegiatan ini sangat urgen karena berdasarkan pengamatan dan penelitian sampai saat ini banyak di antara para pemakai bahasa Indonesia tidak mengenal kaidah-kaidah yang terdapat dalam TBBBI. Mereka bukan hanya para siswa atau mahasiswa, melainkan juga para guru dan dosen. Karena itulah, kegiatan ini wajib dilakukan agar semua pemakai bahasa Indonesia melek terhadap kaidah dalam TBBBI yang sudah dimantapkan.

Pembinaan bahasa juga dapat dilakukan melalui upaya penerapan kaidah tata bahasa pada situasi formal dan karya tulis ilmiah. Salah satu situasi formal yang penting dalam hal ini adalah lembaga pendidikan formal. Penerapan kaidah dapat dimulai dari sana. Hal ini dapat dilakukan dengan memasukkan kaidah tata bahasa ke dalam materi pembelajaran atau perkuliahan di tingkat SD sampai PT. Tentu saja ini dilakukan dengan memperhatikan faktor kejiwaan dan perkembangan siswa/mahasiswa. Kegiatan tersebut merupakan jalan pembuka ke arah penerapan kaidah yang sebenarnya. Dengan jalan itu, kaidahkaidah tata bahasa dapat diterapkan tidak hanya pada situasi-situasi formal, tetapi terutama juga pada karya-karya tulis ilmiah yang disusun mereka. Jika ada pemakaian yang menyimpang dari kaidah pada bahasa mereka, para guru dan dosen 
harus segera mengingatkan dan membenarkan. Kegiatan seperti ini harus dilakukan secara terus-menerus sehingga kaidah yang mantap itu benar-benar diterapkan dalam pemakaian bahasa Indonesia.

\section{METODE PENELITIAN}

Penelitian ini dirancang dalam penelitian deskriptif kuantitatif. Dipilihnya rancangan ini didasarkan pada pertimbangan bahwa penelitian ini bertujuan mendeskripsikan tingkat penguasaan TBBBI oleh guru bahasa Indonesia di Kabupaten Lamongan. Untuk menunjukkan tingkat penguasaan, cara yang paling tepat adalah angka/nilai hasil tes.

Sumber data penelitian ini adalah guru SMA di Kabupaten Lamongan. Jumlah sumber data ditentukan 40 guru SMA. Teknik pengumpulan data yang digunakan dalam penelitian ini adalah teknik tes. Jenis tes yang digunakan untuk mengumpulkan data tentang tingkat penguasaan $T B B B I$ oleh guru bahasa Indonesia berupa tes tertulis yang terdiri atas tes pilihan ganda dan tes isian. Penelitian ini adalah penelitian kuantitatif yang akan menyajikan hasil penelitiannya secara deskriptif kuantitatif.

\section{HASIL DAN PEMBAHASAN}

Tujuan penelitian ini adalah mendeskripsikan tingkat penguasaan TBBBI oleh guru bahasa Indonesia SMA di Kabupaten Lamongan yang diperinci ke dalam beberapa tujuan khusus sebagai berikut: (1) tingkat penguasaan tata bunyi, (2) tingkat penguasaan tata kata, (3) tingkat penguasaan tata kalimat, dan (4) peringkat kesulitan tata bahasa bagi guru bahasa Indonesia SMA.

\section{Tingkat Penguasaan Tata Bunyi oleh} Guru Bahasa Indonesia SMA

Tingkat penguasaan tata bunyi oleh guru bahasa Indonesia SMA di Kabupaten Lamongan dapat dilihat pada tabel di bawah ini.

Tabel 1 Skor Tingkat Penguasaan Tata Bunyi oleh Guru Bahasa Indonesia SMA di Kabupaten Lamongan

\begin{tabular}{cccccc}
\hline No. & Kode & Skor & No. & Kode & Skor \\
\hline 1 & A/SC/BY & $\mathbf{5 0}$ & 21 & A/MT/BY & $\mathbf{6 0}$ \\
2 & A/HD/BY & $\mathbf{5 0}$ & 22 & A $/ A W / B Y$ & $\mathbf{1 0 0}$ \\
3 & A/LS/BY & $\mathbf{8 0}$ & 23 & A/TW/BY & $\mathbf{6 0}$ \\
4 & A/SL/BY & $\mathbf{6 0}$ & 24 & A/TK/BY & $\mathbf{9 0}$ \\
5 & A/ES/BY & $\mathbf{7 0}$ & 25 & A/KL/BY & $\mathbf{9 0}$ \\
6 & A/YD/BY & $\mathbf{5 0}$ & 26 & $\mathrm{~A} / \mathrm{SS} / \mathrm{BY}$ & $\mathbf{6 0}$ \\
7 & $\mathrm{~A} / \mathrm{SC} / \mathrm{BY}$ & $\mathbf{6 0}$ & 27 & $\mathrm{~A} / \mathrm{DS} / \mathrm{BY}$ & $\mathbf{6 0}$ \\
8 & $\mathrm{~A} / \mathrm{AA} / \mathrm{BY}$ & $\mathbf{5 0}$ & 28 & $\mathrm{~A} / \mathrm{AY} / \mathrm{BY}$ & $\mathbf{1 0 0}$ \\
9 & $\mathrm{~A} / \mathrm{SA} / \mathrm{BY}$ & $\mathbf{6 0}$ & 29 & $\mathrm{~A} / \mathrm{PM} / \mathrm{BY}$ & $\mathbf{1 0 0}$ \\
10 & $\mathrm{~A} / \mathrm{AZ} / \mathrm{BY}$ & $\mathbf{7 0}$ & 30 & $\mathrm{~A} / \mathrm{AN} / \mathrm{BY}$ & $\mathbf{6 0}$ \\
11 & $\mathrm{~A} / \mathrm{RN} / \mathrm{BY}$ & $\mathbf{7 0}$ & 31 & $\mathrm{~A} / \mathrm{MM} / \mathrm{BY}$ & $\mathbf{6 0}$ \\
12 & $\mathrm{~A} / \mathrm{AG} / \mathrm{BY}$ & $\mathbf{8 0}$ & 32 & $\mathrm{~A} / \mathrm{WK} / \mathrm{BY}$ & $\mathbf{6 0}$ \\
13 & $\mathrm{~A} / \mathrm{SP} / \mathrm{BY}$ & $\mathbf{1 0}$ & 33 & $\mathrm{~A} / \mathrm{RM} / \mathrm{BY}$ & $\mathbf{9 0}$ \\
14 & $\mathrm{~A} / \mathrm{MZ} / \mathrm{BY}$ & $\mathbf{6 0}$ & 34 & $\mathrm{~A} / \mathrm{MW} / \mathrm{BY}$ & $\mathbf{8 0}$ \\
15 & $\mathrm{~A} / \mathrm{NA} / \mathrm{BY}$ & $\mathbf{5 0}$ & 35 & $\mathrm{~A} / \mathrm{JJ} / \mathrm{BY}$ & $\mathbf{6 0}$ \\
16 & $\mathrm{~A} / \mathrm{HW} / \mathrm{BY}$ & $\mathbf{6 0}$ & 36 & $\mathrm{~A} / \mathrm{Z} / \mathrm{BY}$ & $\mathbf{6 0}$ \\
17 & $\mathrm{~A} / \mathrm{SF} / \mathrm{BY}$ & $\mathbf{6 0}$ & 37 & $\mathrm{~A} / \mathrm{AS} / \mathrm{BY}$ & $\mathbf{4 0}$ \\
18 & $\mathrm{~A} / \mathrm{AZ} / \mathrm{BY}$ & $\mathbf{7 0}$ & 38 & $\mathrm{~A} / \mathrm{MR} / \mathrm{BY}$ & $\mathbf{8 0}$
\end{tabular}




\begin{tabular}{cccccc}
19 & $\mathrm{~A} / \mathrm{SA} / \mathrm{BY}$ & $\mathbf{4 0}$ & 39 & $\mathrm{~A} / \mathrm{PW} / \mathrm{BY}$ & $\mathbf{6 0}$ \\
20 & $\mathrm{~A} / \mathrm{MI} / \mathrm{BY}$ & $\mathbf{1 0 0}$ & 40 & $\mathrm{~A} / \mathrm{TZ} / \mathrm{BY}$ & $\mathbf{6 0}$ \\
& & & Rerata & $\mathbf{6 6}$ \\
\hline
\end{tabular}

Berdasarkan tabel di atas, terlihat bahwa tingkat penguasaan tata bunyi oleh guru bahasa Indonesia SMA tergolong cukup. Simpulan ini dirumuskan berdasarkan rerata skor yang diperoleh mencapai 66.
Tingkat Penguasaan Tata Kata oleh Guru Bahasa Indonesia SMA

Tingkat penguasaan tata kata oleh guru bahasa Indonesia SMA di Kabupaten Lamongan dapat dilihat pada tabel di bawah ini

Tabel 2 Skor Tingkat Penguasaan Tata Kata oleh Guru Bahasa Indonesia SMA di Kabupaten Lamongan

\begin{tabular}{cccccc}
\hline No. & Kode & Skor & No. & Kode & Skor \\
\hline 1 & A/SC/KT & 65 & 21 & A/MT/KT & 60 \\
2 & A/HD/KT & 70 & 22 & A/AW/KT & 65 \\
3 & A/LS/KT & 75 & 23 & A/TW/KT & 85 \\
4 & A/SL/KT & 60 & 24 & A/TK/KT & 70 \\
5 & A/ES/KT & 75 & 25 & A/KL/KT & 60 \\
6 & A/YD/KT & 75 & 26 & A/SS/KT & 65 \\
7 & A/SC/KT & 30 & 27 & A/DS/KT & 55 \\
8 & A/AA/KT & 45 & 28 & A/AY/KT & 65 \\
9 & A/SA/KT & 65 & 29 & A/PM/KT & 55 \\
10 & A/AZ/KT & 85 & 30 & A/AN/KT & 55 \\
11 & A/RN/KT & 90 & 31 & A/MM/KT & 65 \\
12 & A/AG/KT & 85 & 32 & A/WK/KT & 85 \\
13 & A/SP/KT & 15 & 33 & A/RM/KT & 70 \\
14 & A/MZ/KT & 80 & 34 & A/MW/KT & 70 \\
15 & A/NA/KT & 50 & 35 & A/JJ/KT & 65 \\
16 & A/HW/KT & 85 & 36 & A/ZL/KT & 45 \\
17 & A/SF/KT & 25 & 37 & A/AS/KT & 70 \\
18 & A/AZ/KT & 65 & 38 & A/MR/KT & 65 \\
19 & A/SA/KT & 70 & 39 & A/PW/KT & 50 \\
20 & A/MI/KT & 80 & 40 & A/TZ/KT & 60 \\
& & & & Rerata & 64 \\
\hline
\end{tabular}

Berdasarkan tabel di atas, terlihat bahwa tingkat penguasaan tata kata oleh guru bahasa Indonesia SMA tergolong sedang. Simpulan ini dirumuskan berdasarkan rerata skor yang diperoleh mencapai 64.

\section{Tingkat Penguasaan Tata Kalimat oleh Guru Bahasa Indonesia SMA}

Tingkat penguasaan tata kalimat oleh guru bahasa Indonesia SMA di Kabupaten Lamongan dapat dilihat pada tabel di bawah ini.

Tabel 3 Skor Tingkat Penguasaan Tata Kalimat oleh Guru Bahasa Indonesia SMA di Kabupaten Lamongan

\begin{tabular}{cccccc}
\hline No. & Kode & Skor & No. & Kode & Skor \\
\hline 1 & A/SC/KL & 55 & 21 & A/MT/KL & 30 \\
2 & A/HD/KL & 45 & 22 & A/AW/KL & 75 \\
3 & A/LS/KL & 70 & 23 & A/TW/KL & 55 \\
4 & A/SL/KL & 70 & 24 & A/TK/KL & 60
\end{tabular}




\begin{tabular}{cccccc}
\hline \hline & & & & \\
5 & $\mathrm{~A} / \mathrm{ES} / \mathrm{KL}$ & 75 & 25 & $\mathrm{~A} / \mathrm{KL} / \mathrm{KL}$ & 80 \\
6 & $\mathrm{~A} / \mathrm{YD} / \mathrm{KL}$ & 55 & 26 & $\mathrm{~A} / \mathrm{SS} / \mathrm{KL}$ & 55 \\
7 & $\mathrm{~A} / \mathrm{SC} / \mathrm{KL}$ & 40 & 27 & $\mathrm{~A} / \mathrm{DS} / \mathrm{KL}$ & 35 \\
8 & $\mathrm{~A} / \mathrm{AA} / \mathrm{KL}$ & 60 & 28 & $\mathrm{~A} / \mathrm{AY} / \mathrm{KL}$ & 75 \\
9 & $\mathrm{~A} / \mathrm{SA} / \mathrm{KL}$ & 75 & 29 & $\mathrm{~A} / \mathrm{PM} / \mathrm{KL}$ & 75 \\
10 & $\mathrm{~A} / \mathrm{AZ} / \mathrm{KL}$ & 80 & 30 & $\mathrm{~A} / \mathrm{AN} / \mathrm{KL}$ & 55 \\
11 & $\mathrm{~A} / \mathrm{RN} / \mathrm{KL}$ & 75 & 31 & $\mathrm{~A} / \mathrm{MM} / \mathrm{KL}$ & 60 \\
12 & $\mathrm{~A} / \mathrm{AG} / \mathrm{KL}$ & 45 & 32 & $\mathrm{~A} / \mathrm{WK} / \mathrm{KL}$ & 55 \\
13 & $\mathrm{~A} / \mathrm{SP} / \mathrm{KL}$ & 60 & 33 & $\mathrm{~A} / \mathrm{RM} / \mathrm{KL}$ & 60 \\
14 & $\mathrm{~A} / \mathrm{MZ} / \mathrm{KL}$ & 85 & 34 & $\mathrm{~A} / \mathrm{MW} / \mathrm{KL}$ & 70 \\
15 & $\mathrm{~A} / \mathrm{NA} / \mathrm{KL}$ & 55 & 35 & $\mathrm{~A} / \mathrm{JJ} / \mathrm{KL}$ & 55 \\
16 & $\mathrm{~A} / \mathrm{HW} / \mathrm{KL}$ & 55 & 36 & $\mathrm{~A} / \mathrm{ZL} / \mathrm{KL}$ & 35 \\
17 & $\mathrm{~A} / \mathrm{SF} / \mathrm{KL}$ & 20 & 37 & $\mathrm{~A} / \mathrm{AS} / \mathrm{KL}$ & 65 \\
18 & $\mathrm{~A} / \mathrm{AZ} / \mathrm{KL}$ & 80 & 38 & $\mathrm{~A} / \mathrm{MR} / \mathrm{KL}$ & 70 \\
19 & $\mathrm{~A} / \mathrm{SA} / \mathrm{KL}$ & 70 & 39 & $\mathrm{~A} / \mathrm{PW} / \mathrm{KL}$ & 55 \\
20 & $\mathrm{~A} / \mathrm{MI} / \mathrm{KL}$ & 45 & 40 & $\mathrm{~A} / \mathrm{TZ} / \mathrm{KL}$ & 60 \\
& & & & 60 \\
\hline
\end{tabular}

Berdasarkan tabel di atas, terlihat bahwa tingkat penguasaan tata kalimat oleh guru bahasa Indonesia SMA tergolong sedang. Simpulan ini dirumuskan berdasarkan rerata skor yang diperoleh mencapai 60.

Peringkat Kesulitan Tata Bahasa bagi Guru Bahasa Indonesia SMA

Peringkat kesulitan tata bahasa bagi guru bahasa Indonesia bagi guru bahasa Indonesia SMA yang paling tinggi adalah tata kalimat (skor 60), disusul berturut-turut tata kata (skor 64) dan tata bunyi (skor 66).

\section{Pembahasan}

Tingkat penguasaan TBBBI oleh guru bahasa Indonesia SMA di Kabupaten Lamongan tergolong sedang dengan rerata skor 63. Tingkat penguasaan TBBBI itu didukung oleh tingkat penguasaan tata bunyi yang tergolong cukup dengan rerata skor 66, tingkat penguasaan tata kata yang tergolong sedang dengan rerata skor 64 , dan tingkat penguasaan tata kalimat yang tergolong sedang dengan rerata skor 60 .

Peringkat kesulitan tata bahasa bagi guru bahasa Indonesia adalah sebagai berikut. Bagi guru SMA, peringkat kesulitan yang paling tinggi adalah tata kalimat (skor 60), disusul berturut-turut tata kata (skor 64) dan tata bunyi (skor 66).

\section{SIMPULAN DAN SARAN}

Tingkat penguasaan TBBBI oleh guru bahasa Indonesia SMA di Kabupaten Lamongan tergolong sedang dengan rerata skor 63. Tingkat penguasaan tata bunyi oleh guru bahasa Indonesia SMA tergolong cukup dengan rerata skor yang diperoleh mencapai 66 . Tingkat penguasaan tata kata oleh guru bahasa Indonesia SMA tergolong sedang dengan rerata skor yang diperoleh mencapai 64. Tingkat penguasaan tata kalimat oleh guru bahasa Indonesia SMA tergolong sedang dengan rerata skor yang diperoleh mencapai 60.

Bagi guru SMA, peringkat kesulitan yang paling tinggi adalah tata kalimat (skor 60), disusul berturut-turut tata kata (skor 64) dan tata bunyi (skor 66).

Berdasarkan hasil penelitian tersebut, peneliti memberikan beberapa saran berikut. Kepada Badan Bahasa, peneliti menyarankan agar diselenggarakan sosialisasi TBBBI secara intensif kepada para guru terutama guru sekolah dasar karena mereka menjadi ujung tombak dalam pembinaan bahasa Indonesia di lembaga formal. Kepada 
para guru sekolah dasar, peneliti menyarankan agar selalu menimba dan mencari informasi tentang ilmu-ilmu baru termasuk TBBBI ini sehingga ilmu yang disampaikan kepada para siswa tidak ketinggalan zaman.

\section{DAFTAR PUSTAKA}

Alisyahbana, S. Takdir. 1984. "Politik Bahasa Nasional dan Pembinaan Bahasa Indonesia" dalam Amran Halim. Politik Bahasa Nasional 1. Jakarta: PN Balai Pustaka.

Alwi, Hasan dkk. 2000. Tata Bahasa Baku Bahasa Indonesia Edisi Ketiga. Jakarta: Balai Pustaka.

Bahasa Indonesia menuju Bahasa Internasional. Diakses dari http://humanioratamalanrea.blogsp ot.com/2010/11/bahasa-indonesiamenuju-bahasa.html (30 April).

Brown, H. Douglas. 2000. Principles of Language Learning and Teaching (Fourth Edition). New Jersey: Addison Wesley Longman.

Chaer, Abdul. 1993. Gramatika Bahasa Indonesia. Jakarta: Rineka Cipta.

Chaer, Abdul. 1994. Linguistik Umum. Jakarta: Rineka Cipta.

Chaer, Abdul. 2003. Seputar Tata
Bahasa Baku Bahasa Indonesia. Jakarta: Rineka Cipta.

Collins, James T. 2005. Bahasa Melayu Bahasa Dunia: Sejarah Singkat. Jakarta: Yayasan Obor Indonesia.

Halim, Amran (ed.). 1976. Politik Bahasa Nasional. Jakarta: Pusat pembinaan dan Pengembangan Bahasa.

Lanin, Ivan. 2013. "Penguatan Bahasa Indonesia di Dunia Internasional". Makalah pada Sarasehan Kebahasan dan Kesastraan Indonesia Tahun 2013 Balai Bahasa Provinsi Daerah Istimewa Yogyakarta, Hotel Gowongan Inn, Yogyakarta, 23 Oktober 2013.

Medan, Tamsin. 1988. Antologi Kebahasaan. Padang: Angkasa Raya.

Moeliono, Anton M. 1985. Pengembangan dan Pembinaan Bahasa: Ancangan Alternatif di Dalam Perencanaan Bahasa. Jakarta: Djambatan.

Moeliono, Anton M. 1988. Tata Bahasa Baku Bahasa Indonesia. Jakarta: Balai Pustaka.

Yulianto, Bambang. 2007. Aspek Kebahasaan dan Pembelajarannya. Surabaya: Unesa Universitiy Press. 